\title{
Objetivos do Milênio e Democracia Construtiva: os Direitos Fundamentais COMO ElEMENTOS Constitutivos do Estado Democrático de Direito
}

\author{
Carlos Marden Cabral Coutinho* \\ Jose Luis Bolzan de Morais**
}

\begin{abstract}
1 Introdução. 2 Da democracia representativa à democracia construtiva. 3 Para além da democracia liberal: considerações sobre o caráter democrático dos demais direitos fundamentais. $4 \mathrm{O}$ efeito democratizante dos objetivos do milênio. 5 Conclusão: uma "nova" democracia. Referências.
\end{abstract}

\section{RESUMO}

O presente trabalho tem por objetivo demonstrar como a realização dos Objetivos do Milênio se apresenta como um pressuposto para a construção do Estado Democrático de Direito. Para tanto, apresentar-se-á inicialmente uma discussão a respeito do conceito de democracia, com o intuito de demonstrar que (em pleno século XXI) a democracia não pode mais ser vista como um direito limitado de participação política, devendo ser entendida como a capacidade que cada um tem de construir a própria realidade. A partir de tal conceito, buscar-se-á superar o paradigma da democracia liberal clássica, mediante a exposição da lógica segundo a qual o processo ativo da democracia exige que cada pessoa tenha efetiva capacidade de exercer a sua cidadania, o que depende de que lhe sejam oferecidas uma série de oportunidades essenciais para o seu desenvolvimento.

* Possui graduação em Direito pela Universidade Federal do Ceará (2000), especialização em Direito (Processo Civil) pela Universidade Federal do Ceará, mestrado em Direito (Ordem Jurídica Constitucional) pela Universidade Federal do Ceará (2007) e Doutorado (Direito Processual) pela Pontifícia Universidade Católica de Minas Gerais - PUCMinas (2014) . <carlosmardencc@hotmail.com>.

** Possui graduação em Direito pela Universidade Federal de Santa Maria (1984), mestrado em Direito pela Pontifícia Universidade Católica do Rio de Janeiro (1989), doutorado em Direito pela Universidade Federal de Santa Catarina (1995), com estágio \&quot;sanduíche\&quot; na Universidade de Montpellier I - França e Pós-Doutoramento junto à Faculdade de Direito da Universidade de Coimbra. Atualmente é professor da Universidade do Vale do Rio dos Sinos, Procurador do Estado do Estado do Rio Grande do Sul, Coordenador de Núcleo de Estudos da Escola Superior da Magistratura, membro do conselho consultivo do Instituto de Hermenêutica Jurídica, Consultor ad hoc da CAPES, CNPQ, FAPERGS, FAPESC e Università degli studi di Roma Tre e professor convidado da pós-graduação - Universita del Salento , Universita de Firenze, Universidad de Sevilla e Universidade de Coimbra, coordenador do Grupo Estado e Constituição (CNPq).<bolzan@hotmail.com>. 
Nesse contexto, expor-se-á que os Objetivos do Milênio se destacam, na medida em que representam elementos mínimos de condições de uma vida digna, sem os quais se mostra inviável se falar em construção da própria realidade. Por fim, sustentar-se-á que o compromisso com o cumprimento dos Objetivos do Milênio se confunde parcialmente com o compromisso de concretizar o Estado Democrático de Direito, na medida em que representa um passo adequado na ampliação da capacidade de participação efetiva das pessoas que compõem determinada sociedade.

Palavras-chave: Democracia. Perspectiva construtiva. Objetivos do milênio. Função constitutiva.

\section{INTRODUÇÃO}

Em setembro de 2000, 189 (cento e oitenta e nove) países firmaram uma série de compromissos que passaram a ser conhecidos como Objetivos do Milênio. Segundo a "Declaração do Milênio" (celebrada em Nova Iorque), até o final de 2015, os países signatários deveriam atingir 08 (oito) objetivos, os quais são:

a) erradicar a extrema pobreza e a fome;

b) atingir o ensino básico universal;

c) igualdade entre os sexos e a autonomia das mulheres;

d) reduzir a mortalidade infantil;

e) melhorar a saúde materna;

f) combater a AIDS e outras doenças (malária, tuberculose, hanseníase etc.);

g) garantir a sustentabilidade ambiental e;

h) estabelecer uma parceria mundial para o desenvolvimento.

Neste ano em que já se esgotou o prazo de cumprimento desses objetivos, apresenta-se o momento para que seja realizado um balanço de quanto se conseguiu avançar na persecução de metas que eram consideradas distantes no fim do século XX, apesar de referentes a áreas que são tidas como essenciais para o desenvolvimento. De uma maneira geral, trata-se de uma oportunidade para que se possa analisar o estágio de desenvolvimento de cada país signatário (especialmente do Brasil), de forma a traçar novos objetivos que visem a promover ainda mais o desenvolvimento que tem marcado o cenário internacional das últimas décadas. Para isso, o presente trabalho pretende oferecer uma contribuição especifica no que se refere à questão democrática.

Para tanto, será inicialmente discutido o próprio conceito de democracia, destacando que esse sistema deve ser visto como algo que vai muito além das eleições e mesmo de uma forma de governo, devendo a democracia ser concebida em uma perspectiva construtiva, o que significa que o critério de "democraticidade" de uma sociedade deve estar diretamente vinculado à capacidade que as pessoas têm de construir a própria realidade. Desse modo, amplia-se a percepção de que 
a democracia está ligada à elaboração de normas jurídicas, para se entender que existe uma infinidade de normas (de muitas naturezas e dimensões) que regulam a vida das pessoas, motivo pelo qual se deve dar maior atenção à capacidade de ação do indivíduo diante de todo o espectro da realidade e não apenas ao Ordenamento Jurídico (concebido como resultado da atuação estatal).

Partindo da perspectiva construtiva da democracia, será apresentada uma reflexão a respeito da necessidade de que ela seja compreendida muito além da sua concepção liberal. Como será demonstrado, por mais que os direitos fundamentais de primeira dimensão sejam pressupostos do exercício democrático, a ideia de democracia não pode se esgotar neles, sendo indispensável que sofra uma releitura, que permita a absorção dos direitos fundamentais de outras dimensões (notadamente dos chamados direitos sociais). Tal entendimento decorre do fato de que qualquer pretensão de se atribuir a alguém uma real capacidade de construção de sua realidade ultrapassa em muito a simples concessão de liberdade, para incluir um cenário no qual lhe são oferecidos meios para que (co-)configure a realidade como the parecer mais adequado.

Uma vez expostas essas premissas, será aplicado o conceito de democracia construtiva aos Objetivos do Milênio, argumentando que o conteúdo da "Declaração do Milênio" está relacionado não apenas com o desenvolvimento (em sentido estrito), mas também com a própria pretensão de concretizar o Estado Democrático de Direito. Efetivamente, na medida em que os Objetivos do Milênio tratam das questões que são (em escala planetária) consideradas como as mais sensíveis para o desenvolvimento das nações (e, portanto, para a realização da dignidade da pessoa humana), é inevitável perceber a sua relação com a questão democrática, uma vez que se referem a privações que comprometem severamente a pretensão de atribuir às pessoas a capacidade de construir a própria realidade.

Se o século XX foi marcado pela disputa entre modelos econômicos antagônicos (capitalismo e comunismo), nos quais o Estado deveria optar entre uma perspectiva liberal ou social, o século XXI se inicia a partir de um contexto no qual a dignidade da pessoa humana não pode mais ser concebida mediante uma visão restritiva de direitos fundamentais. De fato, o desafio do novo milênio é encontrar uma forma de efetivar todas as dimensões dos direitos fundamentais em um contexto democrático. Essa pretensão pode mostrar-se de difícil abordagem quando se parte de um conceito clássico de democracia (percebida como participação em um sistema de construção de normas jurídicas), mas passa a ser factível quando se adota o conceito de democracia construtiva, pois a realidade das pessoas passa a interessar em sua totalidade.

Os Objetivos no Milênio chegam ao ano de 2015 em diferentes estágios de cumprimento, motivo pelo qual devem ser objeto de profunda análise crítica. Porém, mais importante do que refletir os avanços conquistados em diferentes áreas dos direitos humanos, o balanço da "Declaração do Milênio" deve ser um indicativo de quanto ainda é preciso avançar (e em qual direção) para que se busque o pleno desenvolvimento dos países signatários. Para tanto, acredita-se 
que é fundamental compreender o papel constitutivo que os Objetivos do Milênio têm para o Estado Democrático de Direito. Este trabalho pretende ser uma contribuição neste sentido.

\section{DA DEMOCRACIA REPRESENTATIVA À DEMOCRACIA CONSTRUTIVA}

Surgida na Grécia há cerca de dois mil e quinhentos anos - naquilo que "poderia" ser a época -, a democracia tem uma história cheia de percalços. ${ }^{1}$ Em diferentes momentos dos últimos vinte e cinco séculos, a ideia de um governo democrático passou por diversas releituras, alternando momentos de grande prestígio e de enormes resistências, chegando a ser motivo de revoluções e objeto de longo esquecimento. ${ }^{2}$ No século XX, entretanto, especialmente após a II Guerra Mundial, pode-se verificar que a democracia (ao lado do "neo"constitucionalismo) tem experimentado uma fase de destaque, durante a qual permaneceu décadas sendo objeto não apenas de muitos movimentos sociais que buscavam a sua implantação, mas também de inúmeros escritos que procuravam esboçar uma teoria democrática adequada ao século XX.

Continuando a tradição retomada por Alexis de Tocqueville, ${ }^{3}$ nomes como Hans Kelsen, Raymond Aron e Jürgen Habermas refletiram sobre as características e a funcionalidade da democracia, contribuindo para a releitura da ideia de democracia. De fato, após uma série de contribuições teóricas relevantes, é possível dizer que a democracia chegou ao século XXI com um conceito bem diferente daquele que lhe era atribuído em sua origem grega. Dado o tamanho e a complexidade das sociedades contemporâneas, bem como a consagração da noção de direitos fundamentais (e de constitucionalismo), houve uma convergência teórica em torno do conceito de democracia indireta, que tem como características essenciais a participação (sobretudo eleitoral), a universalidade, a igualdade, a representação e o pluralismo, sem desconsiderarmos os avanços relacionados às fórmulas de participação popular direta.

De maneira sintética, pode-se apontar, em primeiro lugar, que o conceito de participação se incorporou definitivamente ao de democracia. De certo modo, é possível dizer que as ideias sempre estiveram intimamente ligadas (mesmo na democracia grega), porém encontraram uma formulação mais sofisticada na teoria procedimental-discursiva de Jürgen Habermas, ${ }^{4}$ na qual se considera que a democracia consiste na possibilidade de os sujeitos serem autores das normas das quais serão destinatários. Em outras palavras, faz-se uma releitura de todos os movimentos democráticos, identificando entre eles um ponto comum, que é a busca por influenciar a construção do ordenamento jurídico. A história da democracia, portanto, confunde-se com a história da luta para ter participação na gestão do Estado e na elaboração do Ordenamento Jurídico.

Em segundo lugar, pode-se dizer que não é mais concebível se falar em uma democracia nos moldes gregos, na qual o conceito de povo era extremamente 
limitado e a participação era baseada na segregação de grandes segmentos da sociedade (como mulher e escravos). Se uma democracia elitizada representou um grande avanço há vinte e cinco séculos, no terceiro milênio não é possível se trabalhar com um conceito de democracia que não seja baseado na universalidade: o conceito de povo tem que ser o mais amplo possível, admitindo-se apenas exceções em casos extremos (como no caso das pessoas abaixo de certa idade). Atualmente, todos os que escrevem sobre democracia partem da ideia básica de que a democracia não pode ser formalmente excludente, deve acolher em seu seio o máximo de pessoas que estejam aptas a participar.

Da mesma forma, considera-se que a igualdade seja uma característica da democracia, nos termos em que passou a ser concebida a partir do século XX. Na verdade, desde que fez o seu clássico diagnóstico sobre a nascente democracia dos Estados Unidos, Alexis de Tocqueville ${ }^{5}$ destacou que a marca distintiva do regime não estava na forma de governo, mas sim na igualdade entre os cidadãos. É possível perceber, então, que, já desde o século XIX, se considera que as ideias de igualdade e de democracia têm andado juntas, sendo consideradas inseparáveis. Em outras palavras, a concepção de democracia (herdada do século passado) traz em si a percepção fundamental de que não é suficiente que o sistema democrático seja universal, mas exige também que o povo seja constituído por indivíduos iguais entre si.

Partindo dessa concepção de democracia como um sistema no qual todas as pessoas são tidas como iguais e devem ter assegurada a sua participação no processo eleitoral, Hans Kelsen ${ }^{6}$ desenvolve seus escritos sobre o tema (no começo do século XX), sustentando que a democracia direta não é compatível com o tamanho e a complexidade das sociedades atuais, motivo pelo qual a representação deve necessariamente ser tida como um elemento essencial de funcionamento do sistema. Segundo Hans Kelsen, a democracia indireta é um sistema essencialmente representativo. Na medida em que não é possível que milhares (ou mesmo milhões) de pessoas participem diretamente de cada decisão, cabe organizar o sistema de forma a que partidos políticos sejam instrumentos de representação de diferentes parcelas do povo.

Por fim, pode-se apontar que a democracia não deve apenas ser representativa, mas também plural. Como explica Raymond Aron ${ }^{7}$, o sistema representativo não serve para que o processo eleitoral revele uma vontade única popular, mas, pelo contrário, serve para que o processo eleitoral acomode as diversas aspirações dos diferentes segmentos que compõem o espectro social. Trata-se de uma considerável mudança no conceito de democracia, que supera a busca da vontade popular, para ser vista como um sistema de acomodação de diferentes interesses. Efetivamente, não é possível sustentar que existe um objetivo comum a ser buscado por toda a sociedade, mas sim uma série de interesses paralelos (e, muitas vezes, contraditórios e antagônicos) que precisam ser coordenados para que seja possível a convivência em uma sociedade organizada. 
A partir dessas características essenciais, sumariamente indicadas, é possível delinear o conceito de democracia que restou consagrado após as contribuições teóricas do século XX. Partindo da premissa de que a democracia direta é incompatível com o tamanho e a complexidade das sociedades contemporâneas, a democracia passa a ser concebida como um sistema representativo no qual deve ser assegurada a participação do maior número possível de pessoas (todas elas consideradas iguais entre si), com o objetivo de que o Estado reflita a diversidade de valores existente na sociedade. É nisso que se fala quando se fala em democracia no começo do século XXI. É exatamente isso que modula o discurso sobre o tema e a percepção do fenômeno democrático, de maneira que cumpre investigar a adequação de tal conceito.

Acontece que esse conceito de democracia tem um problema fundamental: ao confundir democracia direta com democracia agórica (na qual as pessoas se reúnem em uma praça para deliberar), conclui equivocadamente que a democracia direta seja incompatível com a realidade social do novo milênio. Por via de consequência, busca no sistema representativo uma forma de manter viva a possibilidade de participação universal (e igualitária), o que acaba por transformar o processo eleitoral em um elemento central da democracia. Como resultado, tem-se uma discussão que se foca sobre como eleger pessoas que possam legislar representando o povo, que tem a sua participação efetiva resumida às eleições ou, quando muito, estendida a alguns modestos instrumentos de democracia direta (como o plebiscito e o referendo).

Essa limitação do conceito de democracia, entretanto, não se mostra necessária. De fato, não há qualquer dúvida quanto à inviabilidade de que decisões sejam tomadas mediante deliberação na qual se reúna toda a população de um país, um estado ou mesmo uma cidade. A tal democracia agórica, se não está permanentemente eliminada da vida social, tem hoje, com certeza, um âmbito bastante limitado de aplicação. Entretanto, essa constatação não implica comprometimento da possibilidade de exercício de uma democracia direta, desde que se esteja atento a duas ponderações:

a) a participação democrática está diretamente relacionada ao interesse que as pessoas têm no assunto a ser decidido e;

b) as normas que regulam a vida das pessoas (e de cuja confecção se pretende participar) nem sempre têm caráter jurídico-formal.

Tais observações merecem maior elaboração.

O primeiro problema dessa concepção (formal) de democracia é que ela parte da ideia de que o tamanho e a complexidade das sociedades contemporâneas desfere um golpe fatal em qualquer pretensão de operacionalizar um sistema de democracia direta. Efetivamente, não é de se imaginar que seja possível promover a reunião de todo o povo na praça para fins deliberativos, trata-se de um projeto que deixou de ser factível. Entretanto, essa objeção é apresentada sem que se enfrente uma questão preliminar, qual seja: é realmente necessário 
que todo o povo delibere - sobre todas as questões - para que a decisão tenha caráter democrático? Não há dúvida de que a resposta negativa se impõe. Por mais que atualmente a universalidade seja uma característica indissociável da democracia, a exigência para a participação de todos significa a participação de todos os que são interessados.

Ora, quantas questões a serem decididas (ou quantas normas a serem elaboradas) realmente interessam a todas as pessoas que compõem uma comunidade? Com certeza, algumas situações poderão ser mesmo consideradas de interesse geral, no sentido de que a sua regulamentação interessa a todos os indivíduos de determinado grupo. Porém, também é seguro afirmar que essas situações serão excepcionais, ou seja, na esmagadora maioria das vezes, as questões a serem discutidas e regulamentadas interessam a subgrupos da comunidade, os quais podem, sim, ter número suficiente para que seja viável a sua reunião pessoal, bem como o debate e a decisão em caráter direto. Não se trata de definir subgrupos que decidam em nome do grupo completo, mas sim de perceber que cada subgrupo pode decidir aquilo que é de seu interesse exclusivo e que não repercuta sobre interesse de outros grupos ou de toda a comunidade.

Dentro dessa lógica, é possível realizar uma inversão de perspectiva, com o intuito de deslocar o centro de discussão/produção das normas. Na verdade, o que se propõe é que o indivíduo possa refletir sobre as questões (excepcionais, mas certamente existentes) que são de seu interesse exclusivo, tendo reconhecida a sua capacidade de elaborar a norma que lhe pareça mais apropriada. Uma vez que a questão seja de interesse além da esfera individual, então a mesma lógica deve-se aplicar à família, à sociedade comercial, ao condomínio, à associação, ao bairro, à cidade etc. Uma vez que determinado grupo se depare com uma situação que interessa apenas a ele e que não vá gerar efeitos em outro grupo (em outro condomínio, por exemplo), então deve ser-lhe assegurada a possibilidade de regular a questão como melhor convier.

A razão aqui é bastante simples: a inclusão de novas pessoas no processo decisório promove uma inevitável erosão democrática, na medida em que, em grupos maiores, o interessado perde espaço discursivo e poder decisório. Em uma escala máxima, o indivíduo tem plena liberdade para decidir sobre aquilo que diga respeito somente a si mesmo, mas tal influência vai sendo diluída na medida em que os grupos aumentam de número, até que seja inviável a participação direta e se fale em representação. Parece ser certo considerar que esse aumento do grupo (pela inserção de novos interessados) é inevitável, porém deve ser admitido de maneira controlada, tendo em vista esta "erosão" democrática que provoca. Nesse sentido, então, pode-se falar da existência de um princípio da influência exclusiva, segundo o qual os interessados têm direito a que apenas eles próprios participem do debate e da decisão que interessam apenas ao seu subgrupo.

Afinal de contas, por que deveria ser assegurado a alguém o direito de discurso e de voto a respeito de uma questão que não lhe diz respeito de maneira nenhuma? É difícil acreditar que se possa encontrar sustentação teórica para a 
pretensão de diluir a participação dos interessados, mediante incremento do grupo com uma parcela de não interessados, até que se chegue em uma situação em que a democracia direta é inviável. O primeiro ponto a ser esclarecido, portanto, é que a democracia indireta só é inviável para grandes grupos e estes só precisam ter influência em decisão que digam respeito a algo que efetivamente interesse a tantas pessoas, que seja impossível reuni-las para deliberação direta. ${ }^{8}$ De maneira geral, entretanto, é possível pensar em uma democracia policêntrica, na qual cada subgrupo social pode ser considerado emissor das normas que hão de regular as questões que lhes dizem respeito exclusivo.

Essa proposição provavelmente pode parecer estranha (ou mesmo desconfortável) à primeira vista. Tal sensação incômoda decorre do fato de que a democracia tem sido usualmente pensada como sendo um sistema de produção de normas jurídicas, por intermédio do Parlamento. Trata-se, então, de uma concepção que parte da premissa de que a democracia se relaciona diretamente com o Estado, enquanto ente emissor de normas que regulam a vida dos cidadãos. Mesmo que se sustente que o povo deve ter maior participação possível no processo, ainda se trata de uma concepção de fundo autoritário, na medida em que centraliza no Estado a produção de normas formais para a regulação das condutas praticadas na sociedade. Como observado há pouco, entretanto, a democracia pode ser policêntrica; nada em sua essência exige que haja apenas um núcleo de produção de normas ou regras de conduta e convívio.

Aqui, exige-se uma reflexão sobre a questão. Pegue-se o indivíduo. Em cada um de seus dias, uma série de condutas é exclusivamente de seu interesse: o horário em que ele resolve dormir; de que se alimenta; se irá ler ou ver televisão; qual roupa vestirá para cada ocasião; que percurso irá seguir entre um local e outro de suas atividades etc. São pequenas questões que interessam a ele e a mais ninguém, de modo que lhe é dada a possibilidade de regular a sua conduta da maneira que melhor entender. Enquanto um sujeito prefere aproveitar mais horas de sono, outro acredita que dormir muito é perda de tempo; enquanto um sujeito prefere ser vegetariano, outro prefere o prazer da carne vermelha; enquanto um sujeito relaxa com literatura, outro prefere ver futebol e um terceiro divide-se entre a televisão e os livros e assim por diante. Em todas essas situações, as decisões tomadas por um dos sujeitos não afeta, de nenhuma maneira, a forma como se dará a conduta do outro.

Pergunta-se, então: o que impede que o sujeito possa estabelecer para si mesmo a norma que bem entender em relação àquela conduta que diz respeito somente a si mesmo? A resposta que se impõe é a seguinte: nada!

A priori, não há motivo para que se estabeleçam limites para a forma como o sujeito regula as suas condutas individuais, salvo naquilo que elas afetam outras pessoas. O que ocorre é que essa conduta intersubjetiva (quando a situação interessa a mais de uma pessoa) acaba por ser a regra quando se vive em sociedade, fazendo que sejam residuais os casos nos quais determinada conduta diz respeito apenas a quem a pratica (assim como também são excepcionais os casos nos quais 
as questões interessam a toda a comunidade). Tem-se, então, que a liberdade de conduta do indivíduo se encontra no espectro oposto do fenômeno social, em relação àqueles casos da democracia representativa.

Tal constatação, entretanto, em nada prejudica o raciocínio desenvolvido. A mesma lógica da influência exclusiva pode ser aplicada à medida que os grupos forem crescendo, de forma que se assegure ao casal a possibilidade de ser um centro emissor das normas jurídicas que regula situações que lhe dizem respeito exclusivo (o destino de sua viagem de férias ou o nome que darão ao seu filho, por exemplo). ${ }^{9}$ Da mesma maneira, pode-se estabelecer que o caráter policêntrico da democracia exige que se reconheça cada subgrupo social (como os integrantes de um condomínio de apartamentos, os sócios de determinada empresa ou os moradores de um bairro) como capaz de emitir as normas que irão regular as respectivas condutas nos assuntos de seu interesse exclusivo, sem que se admita a influência/participação de qualquer um que não seja interessado na questão.

Contra tal proposta, certamente se apresentará a objeção de que existe uma diferença de natureza entre a decisão a respeito do destino das férias do casal e aquela consistente em tipificar um crime. Por tal motivo, essa proposta requer a desconstrução da relação íntima que se convencionou estabelecer entre a democracia e a produção de normas jurídicas formais. Apesar da tendência instintiva a restringir o fenômeno democrático à produção de direito, tal limitação não é adequada, visto que não existe nenhuma questão que seja jurídica por natureza. De fato, o que define qual questão será pertinente ao direito é o próprio direito, de maneira que absolutamente qualquer conduta no mundo pode adquirir natureza jurídica, bastando, para tanto, que o legislador resolva regulá-la (vide a Coreia do Norte, na qual existe norma a respeito de qual corte de cabelo é autorizado aos cidadãos). ${ }^{10}$

Tem-se, portanto, que não é possível estabelecer um corte ontológico entre o que é jurídico ou não, uma vez que cabe ao próprio Ordenamento Jurídico indicar onde se encontra o seu limite. Na verdade, sustentar uma divisão entre o jurídico e o não jurídico significa olvidar um dos problemas mais relevantes da democracia, qual seja o de saber até onde o direito pode avançar na regulação de condutas. A diferença entre um sistema democrático e um autoritário não se limita apenas a saber se o processo legislativo tem elementos típicos da democracia, mas tem um alcance muito mais amplo, incluindo a definição mesma de se saber o que pode/deve ser submetido ao processo legislativo formal. Essa questão não pode ser respondida pelo conceito clássico de democracia.

Para superar esse dilema e responder devidamente à pergunta, é preciso um novo paradigma, que possibilite compreender que um Estado autoritário não é apenas aquele que emite normas resultantes de um processo legislativo no qual não se assegurou participação popular. Também deve ser considerado autoritário aquele Estado que submete à vontade geral (seja mediante Parlamento ou mesmo plebiscito) uma questão que não diz respeito a todo o povo. No primeiro caso, o elemento autoritário está presente pela exclusão da participação; no segundo caso, por se verificar uma erosão desnecessária da influência democrática dos 
destinatários da decisão. Em ambos os casos, existe ofensa frontal ao princípio democrático, à medida que os destinatários das normas sofrem prejuízo na sua capacidade de produção da norma que há de regular a sua conduta. Pode-se dizer que há um "deficit democrático" pela falta de participação ou por seu excesso.

Todo esse grupo de constatações exige uma verdadeira releitura do conceito de democracia. Aqui, não é preciso descartar todas as contribuições teóricas acumuladas ao longo dos últimos séculos, basta apenas mudar o foco. Assim como Jürgen Habermas ${ }^{11}$ percebeu que, em todas as suas fases, a democracia sempre disse respeito à questão da participação da construção de normas, o que se pretende é destacar que, ao longo de toda a sua história, o máximo denominador comum do ideal democrático sempre foi a busca para que as pessoas tenham o máximo possível de influência na definição das normas que hão de regular as próprias condutas. Em outras palavras, democracia pode ser redefinida como sendo a capacidade de cada um de construir a própria realidade, o que significa que uma sociedade será tão mais democrática quanto maior for a capacidade que cada um tem de construir a realidade em que está inserido.

Como afirmado, essa mudança de foco não implica contestação de todas as teorias consolidadas sobre a democracia, mas sim a busca de encontrar um ponto de convergência entre elas, bem como com a realidade do novo milênio. De plano, já é possível perceber que a mudança de paradigma promove um deslocamento do centro gravitacional da democracia, que deixa de ser a produção estatal de normas, para ser a realidade individual de cada integrante do povo. Há uma inversão da lógica democrática, fazendo que a democracia direta passe a ser a regra. De acordo com essa lógica, o sistema representativo continua a ser indispensável (uma vez que muitas situações ainda serão objeto de deliberação indireta), mas ele deixa de ser elemento central, para ser um elemento, entre outros, do sistema.

Como é de se imaginar, essa mudança de foco vai exigir uma releitura não apenas da discussão a respeito da democracia representativa, mas de todo o fenômeno democrático, exigindo novas reflexões que vão desde a investigação de quem tem legitimidade democrática para decidir cada questão até mudanças estruturais profundas nos sistemas e processos eleitorais e/ou legislativos. Tais aprofundamentos, entretanto, escapam ao objeto do presente trabalho, motivo pelo qual os tópicos seguintes se limitarão a investigar qual o papel que a chamada democracia construtiva reserva para os direitos sociais, bem como analisar de que forma esse novo conceito pode acomodar os Objetivos do Milênio, reservando-lhes o papel de destaque que eles têm para o desenvolvimento.

\section{PARA ALÉM DA DEMOCRACIA LIBERAL: CONSIDERAÇÕES SOBRE O CARÁTER DEMOCRÁTICO DOS DEMAIS DIREITOS FUNDAMENTAIS}

Conforme exposto, o conceito de democracia usualmente trabalhado no final do século XX e no início do século XXI apresenta um deficit teórico em decorrência 
da percepção míope que tem em relação ao tipo de normas que são relevantes para vida das pessoas, o que faz que atribua exagerada importância à questão da representação, olvidando a análise de inúmeras normas de caráter mais concreto e que podem ser construídas de maneira direta (pelo cidadão ou pelos pequenos grupos). Trata-se de um equívoco cuja relevância não pode ser superestimada, tendo em vista que contamina todos os aspectos do debate a respeito da democracia, na medida em que concentra o discurso em um assunto periférico (o sistema representativo) e ignora o elemento central do sistema: a possibilidade de contribuir diretamente para a elaboração de normas, sem necessidade de representação.

Tal problema não pode ser resolvido no interior desse paradigma, tendo em vista que a concepção clássica de democracia parte do pressuposto equivocado de que a democracia direta é impraticável. Exige-se, portanto, utilização de um novo paradigma, que possibilite entender o fenômeno democrático como sendo algo que diz respeito a todas as normas que regulam a vida da pessoa e não apenas às normas jurídicas oriundas (em regra) do Parlamento. A proposta da democracia construtiva pretende atender a exatamente essa necessidade, visto que concebe a democracia como a capacidade que cada um tem de construir a própria realidade, assim considerada a regulação de condutas não apenas por normas jurídicas, mas também sociais e mesmo individuais. Porém, existe outro ganho sistêmico da mudança de paradigma que se propõe, qual seja, a possibilidade de permitir que a democracia dialogue com todas as dimensões dos direitos fundamentais. ${ }^{12}$ Explica-se.

Quando se toma a concepção clássica de democracia (exposta no tópico anterior), existe uma relação direta que se estabelece entre ela e os direitos fundamentais de primeira dimensão, a saber, os direitos políticos e de liberdade. Efetivamente, não há como questionar a ligação estreita e umbilical que existe entre a democracia e o direito de votar e de ser votado, por exemplo. Da mesma maneira, nos últimos dois séculos, pode-se dizer que se tratou exaustivamente da relação da democracia com direitos como liberdade de expressão, liberdade de associação, liberdade de ir e vir etc. Não é à toa que se usa normalmente o adjetivo liberal para qualificar a democracia, uma vez que ela se concentra prioritariamente nos direitos fundamentais de algum modo relacionados à liberdade.

Destaque-se que não se está aqui a dizer que os teóricos da democracia sejam avessos aos demais direitos fundamentais. Certamente não o são. $\bigcirc$ que acontece é que tais direitos fundamentais de outras dimensões simplesmente não são considerados como sendo relevantes para a discussão da questão democrática. De fato, se a democracia é concebida apenas como o direito de participar politicamente do processo eleitoral em condições iguais às dos demais, então o foco vai se concentrar essencialmente nos direitos fundamentais de primeira geração, uma vez que a democracia assume um caráter extremamente formal. As normas serão democráticas desde que oriundas de processos que tenham assegurado participação mediante discurso. Não há, portanto, necessidade de investigar o grau de efetividade dos demais direitos fundamentais. Trata-se de uma questão paralela e alheia à busca de uma sociedade mais democrática. 
Essa é uma limitação extremamente grave da teoria democrática, o que faz que o termo democracia liberal seja visto mesmo como pejorativo. O problema, entretanto, não é intrínseco à democracia e só se apresenta porque (mais uma vez) se parte de um conceito equivocado do fenômeno. A partir do momento em que se adota a perspectiva construtiva e se passa a medir o quão democrática é uma sociedade a partir do grau de capacidade de cada um para construir a própria realidade, então passa a ser fácil superar o problema, promovendo a compatibilização da democracia com todas as dimensões dos direitos fundamentais. Não se trata de dizer que a democracia construtiva não seja liberal, pois não há dúvida de que o seja, na medida em que os direitos políticos e de liberdade lhe são essenciais. Porém, ela transcende os limites típicos da democracia liberal, exigindo outras dimensões dos direitos fundamentais em sua constituição.

A questão se põe nos seguintes termos: a perspectiva construtiva amplia o foco de interesse da democracia, fazendo que sejam relevantes não apenas as normas jurídicas (normalmente oriundas do Parlamento), mas também toda e qualquer norma que venha a regular a conduta do indivíduo em qualquer aspecto da sua vida. Uma vez que se recusa que existam aspectos da vida que sejam afeitos ao direito (enquanto outros não seriam), então cada pessoa está quase integralmente sujeita a inúmeras normas que disciplinam a sua conduta, motivo pelo qual ela tem interesse direto em influenciar na confecção delas. Em uma situação normal, cada um vai tentar ter o máximo de influência possível na construção da própria realidade, o que se dá mediante a elaboração (o mais direta possível) de normas que lhe tenham como destinatário.

Sendo assim, como se tem uma perspectiva holística da regulação de conduta do indivíduo, então não há como deixar de lado alguns grupos de direitos fundamentais, para se concentrar apenas naqueles que dizem respeito à liberdade e ao exercício político. Ora, por mais que os direitos fundamentais de primeira dimensão sejam elementos básicos da democracia construtiva, a própria forma como ela é concebida exige que as outras dimensões dos direitos fundamentais também se apresentem como sendo de nível constitutivo, uma vez que ninguém vai efetivamente construir a própria realidade de maneira livre se lhe forem dadas apenas condições formais para tanto. Uma breve digressão nas outras dimensões dos direitos fundamentais será suficiente para mostrar como elas se relacionam com a democracia construtiva, de modo a tornar impossível a desconexão dos conceitos.

De uma forma resumida, pode-se dizer que a doutrina reconhece que, além dos direitos políticos e de liberdade, existem as seguintes dimensões dos direitos fundamentais:

a) segunda (consistente nos direitos sociais como saúde, educação, moradia, segurança etc.);

b) terceira (consistente nos direitos coletivos/difusos como o meio ambiente, o desenvolvimento, o patrimônio histórico, artístico e cultural etc.);

c) quarta (consistente nos direitos de universalidade como a informação, o pluralismo, a democracia etc.) e; 
d) quinta (consistente no direito à paz, como pressuposto para a viabilidade da concretização das demais dimensões).

Apesar de a classificação ter um evidente caráter didático, ainda assim tem importância ilustrativa para que se perceba a forma como se tem admitido ou não a conexão dos diversos direitos fundamentais com a democracia.

Um primeiro indício dessa distorção pode ser constatado pelo simples fato de a democracia em si ser considerada como um direito fundamental de quarta geração, ou seja, como se ela pudesse ser assegurada independentemente da concretização dos demais direitos fundamentais de outras ou mesma dimensão. Essa percepção equivocada só é possível porque se entende que a democracia seja o direito de participar ativamente da vida política e do sistema eleitoral, prioritariamente mediante um sistema representativo, no qual todas as pessoas capazes sejam consideradas iguais. Por mais complexa e relevante que se mostre esse conceito, ele praticamente se esgota dentro da primeira dimensão dos direitos fundamentais, porque historicamente não passa de uma releitura atualizada daquela democracia concebida no fim do século XVIII e no começo do século XIX, quando a dignidade da pessoa humana era relacionada exclusivamente com os direitos políticos e de liberdade.

Efetivamente, se o paradigma adotado for o da democracia indireta/representativa, o que se pode querer mais do que um Estado que assegure liberdade (de crença, associação, manifestação, expressão etc.) e direitos políticos? Por mais que se defenda a existência e a concretização das outras dimensões dos direitos fundamentais, tratar-se-á inevitavelmente de uma discussão paralela, não relacionada com a democracia. De fato, talvez seja até possível estabelecer uma conexão entre a educação, por exemplo, e a democracia. Entretanto, como estabelecer uma relação entre a democracia e o fato de uma determinada pessoa não viver em um local no qual se sinta segura ou o fato de ela não ter onde morar? Como se relacionar o direito ao meio ambiente ou a cultura com uma democracia concebida como sistema/processo eleitoral? Em que termos interessa ao debate democrático a existência de paz em um determinado território?

Por mais relevantes que sejam as questões relacionadas a tais direitos fundamentais, elas não podem ser seguramente transpostas para o debate sobre democracia, porque o conceito liberal de democracia representativa/indireta não possui fundamentos que comportem discutir todas as dimensões dos direitos fundamentais. Para que seja possível compatibilizar todos os direitos fundamentais com a questão democrática, é preciso um novo paradigma (que seja mais abrangente do que aquele focado no sistema eleitoral-representativo) capaz de revelar o fato de que a democracia diz respeito não apenas às normas jurídicas, mas a todas as normas que regulam a conduta das pessoas em todos os âmbitos de sua vida. Tal ganho sistêmico é possível mediante adoção da perspectiva construtiva, que concebe a democracia como capacidade para cada um construir a própria realidade. 
Funciona da seguinte maneira: a partir do momento em que se transcende o limite estrito das normas jurídicas, passa-se a entender que a capacidade de construir a realidade em regra acontece de maneira direta e só excepcionalmente de maneira indireta e/ou representativa. Nesse contexto, passa a ser objeto de interesse do debate democrático todas as decisões que o ser humano toma em seu cotidiano, desde o corte de cabelo que escolhe até as regras do condomínio, passando pelo destino das férias da família. Sozinho ou com seus pares cointeressados na questão, cada pessoa está permanentemente envolvida na elaboração de regras que hão de regular a sua conduta, motivo pelo qual deve lhe ser assegurado o máximo possível de influência em sua construção. Toda e qualquer limitação indevida e desnecessária da liberdade do indivíduo implica erosão democrática, visto que o impede de construir a sua própria realidade.

O diferencial dessa perspectiva é que a liberdade não precisa ser concebida apenas de maneira formal, assim entendida uma perspectiva negativa, segundo a qual outras pessoas (ou o Estado) não devem impedir que o ser humano se comporte da maneira que entende devida. Como a liberdade aqui é para construir a própria realidade, então não há como dissociar a sua efetividade da existência de todos os meios que são pertinentes à referida construção. Sendo assim, pode-se, de imediato, estabelecer uma relação de dependência entre a democracia e todos os direitos fundamentais, uma vez que as suas variadas dimensões revelam apenas novas perspectivas da dignidade da pessoa humana. Para muito além dos direitos fundamentais de primeira dimensão, a democracia vai se relacionar com direitos que podem ser sociais, coletivos ou de qualquer natureza, porque, no fim das contas, assim como ela, todos dizem respeito à dignidade da pessoa humana.

Aqui a democracia se aproxima do conceito de desenvolvimento como liberdade apresentado por Amartya Sen, ${ }^{13}$ segundo o qual desenvolvimento é a capacidade que as pessoas têm para levar a vida que elas têm razão para valorizar. Da mesma forma, democracia é a capacidade para cada um (co-)construir a realidade da maneira que parecer mais adequada aos interessados. Entretanto, como se pode imaginar que alguém tenha essa capacidade, se não gozar de saúde ou tiver recebido educação básica? Como imaginar que alguém possa construir a própria realidade se vive em um ambiente no qual não lhe é garantida a segurança? Além disso, que tipo de capacidade construtiva é reservada àquele que vive na rua, pois não tem uma moradia na qual possa encontrar abrigo permanente? Não há como separar os direitos fundamentais sociais do conceito de democracia construtiva, porque eles dizem respeito a elementos mínimos para que alguém tenha capacidade de influir na própria realidade.

A mesma lógica pode ser aplicada aos direitos fundamentais de terceira, quarta ou quinta geração. Se o meio ambiente pode parecer algo com pouca (ou mesmo nenhuma) relação com a democracia representativa, a realidade é completamente outra quando se trata da democracia construtiva, pois fica evidente que o meio ambiente é essencial para estabelecer limites dentro dos quais a pessoa pode construir a própria realidade. Assim também, é fácil estabelecer como a 
democracia construtiva se relaciona, por exemplo, com o direito à informação, requisito fundamental para que a pessoa esteja consciente de todos os elementos envolvidos em qualquer decisão que tome e venha a impactar futuramente na própria vida. Mesmo o direito à paz pode ser enquadrado dentro do esquema teórico da democracia construtiva, na medida em que um quadro de guerra transtorna de tal maneira os mais diversos aspectos cotidianos, que impõe severas limitações à capacidade que qualquer um possa ter de influenciar o estabelecimento das normas que entende mais pertinentes para regular a própria vida.

Diante dessas observações, fica claro o ganho sistêmico decorrente da mudança de paradigma representada pela substituição do conceito de democracia representativa (ou mesmo participativa) pelo conceito de democracia construtiva. Uma vez ampliado o objeto de interesse da democracia (para incluir todos os aspectos da vida da pessoa que podem ser regulados por normais pessoais, grupais, sociais ou estatais), o desafio de construir a própria realidade passa não apenas pela efetivação dos direitos políticos e de liberdade, mas também pela concretização de todas as dimensões dos direitos fundamentais. ${ }^{14}$ Isso acontece porque a democracia também deve ser estudada sob uma perspectiva que a perceba como uma manifestação legítima da busca de cada um por uma vida repleta de dignidade.

\section{O EFEITO DEMOCRATIZANTE DOS OBJETIVOS DO MILÊNIO}

A inadequação da teoria democrática mais difundida vai além do problema de foco: consistente em isolar o aspecto jurídico dos demais aspectos das vidas das pessoas, fazendo que a produção de normas jurídicas (e consequentemente o sistema representativo) assuma um papel central que promove uma inevitável distorção na concepção de democracia. Efetivamente, conforme demonstrado no tópico anterior, mesmo uma releitura da democracia que favoreça o seu aspecto direto (privilegiando iniciativa de lei, plebiscito e referendo, por exemplo), ainda se encontra contaminada pela concepção limitada da representação, fazendo a democracia seja vista exclusivamente sob uma perspectiva liberal, que esgota o seu objeto mediante otimização da efetividade dos chamados direitos fundamentais de primeira dimensão.

Esse problema, entretanto, pode ser não apenas afastado (ou evitado), mas efetivamente superado pela concepção de democracia construtiva. De fato, a partir do momento em que se muda o paradigma democrático e se passa a entender que uma sociedade é tão mais democrática quanto maior for a capacidade que seus membros têm de construir a própria realidade, não há qualquer óbice à compatibilização entre os direitos fundamentais de quaisquer dimensão e o conceito de democracia. Especificamente no que diz respeito aos direitos sociais, a questão vai além da mera convergência entre os temas, para implicar mesmo que se entende que tais direitos fundamentais são pressupostos da democracia construtiva. Afinal, quem pode ter capacidade de construir a própria realidade, se não tiver saúde, educação, segurança e moradia? ${ }^{15}$ 
Essa mesma lógica deve ser aplicada aos 08 (oito) Objetivos do Milênio:

a) erradicar a extrema pobreza e a fome;

b) atingir o ensino básico universal;

c) igualdade entre os sexos e a autonomia das mulheres;

d) reduzir a mortalidade infantil;

e) melhorar a saúde materna;

f) combater a AIDS e outras doenças (malária, tuberculose, hanseníase etc.);

g) garantir a sustentabilidade ambiental; e

h) estabelecer uma parceria mundial para o desenvolvimento.

A pequena lista de metas elaborada pelo Programa das Nações Unidas para o Desenvolvimento não deve ser vista exclusivamente sob o aspecto social, mas também como uma forma de incremento democrático, visto que esgotá-la implica diretamente no aumento da capacidade das pessoas para construir a própria realidade, motivo pelo qual é pertinente uma análise de como alguns desses objetivos se relacionam com a questão democrática.

Em primeiro lugar, coloca-se como Objetivo do Milênio a erradicação da pobreza e da fome. A importância de tal objetivo dispensa maiores comentários, na medida em que a pobreza extrema e a fome comprometem a própria existência do ser humano, com repercussão direta sobre todos os seus direitos fundamentais. Especificamente no que toca à questão democrática, o comprometimento da capacidade também é avassalador, porque é evidente que aquele que não tem condições de atender às suas necessidades mais básicas jamais irá apresentar-se como um ser político, no sentido de ter atuação proativa na esfera pública, buscando fazer prevalecer o seu discurso sobre as normas das quais eventualmente virá a ser destinatário. A situação de extrema pobreza e fome compromete a experiência da cidadania e a viabilidade de qualquer forma de democracia.

Essa constatação, entretanto, assume uma versão ainda mais drástica quando se utiliza o conceito de democracia construtiva, porque o foco muda e a questão democrática passa a englobar todos os aspectos da vida da pessoa, reconhecendo que normas não jurídicas também são relevantes e exigem que sua formação se dê da maneira adequada. Sendo assim, a exclusão provocada pela fome e pela pobreza é ainda mais significativa, pois aquele que se vê assolado por esses problemas estará não apenas impedido de contribuir para a construção do Ordenamento Jurídico, mas também para construir a própria realidade, a própria vida. No nível mais fundamental possível, a pobreza extrema e a fome impedem qualquer tipo de influência democrática, fazendo que a pessoa necessitada seja dependente da vontade alheia em cada pequeno aspecto de sua vida, sob pena de perecer.

Quanto à questão do perecimento, cumpre destacar que também foi convencionado como Objetivo do Milênio o intuito de reduzir em dois terços a mortalidade de crianças até os 05 (cinco) anos de idade. Normalmente, dada a sua falta de capacidade para a atuação política, as crianças são entendidas como excluídas das discussões a respeito da democracia, o que pode parecer uma 
postura natural para a teoria clássica da democracia, mas não é compatível com a perspectiva da democracia construtiva. Como é evidente, se a democracia é concebida como capacidade para a construção da própria realidade, não cabe excluir nem mesmo as crianças de seu objeto de análise. A uma, porque mesmo as crianças (que não podem participar ativamente da política) têm alguma esfera de autonomia na qual sua vontade prevalece. A duas, porque sobreviver é um pressuposto para o exercício de qualquer direito, incluindo aqueles considerados típicos da democracia.

Outros Objetivos do Milênio relacionados com a questão são aqueles consistentes em melhorar a saúde materna (incluindo a redução em três quartos da mortalidade materna e o acesso universal á saúde reprodutiva) e combater (reduzindo ou eliminando) doenças graves, assim consideradas a AIDS, a malária, a tuberculose e a hanseníase. Mais uma vez, o Programa das Nações Unidas para o Desenvolvimento assume a postura de privilegiar o combate a problemas relacionados com a sobrevivência e com a saúde, demonstrando o entendimento de que uma vida saudável é pressuposto para que se fale em dignidade de qualquer pessoa. Da mesma forma, trata-se também de questões relacionadas com a democracia, na medida em que a capacidade de construir a própria realidade depende essencialmente de que a pessoa esteja viva e com saúde.

Aqui, cabe uma reflexão. A mudança de paradigma representada pela democracia construtiva tem o efeito claro de deslocar a questão da representação (e da formação de normas jurídicas) para a periferia do processo democrático, mas é preciso destacar que isso implica deslocamento de outros tipos de normas (principalmente aquelas referentes à regulação de situações que dizem respeito somente ao indivíduo ou ao grupo) para o centro gravitacional do fenômeno democrático. Com essa mudança, a questão da saúde ganha uma relevância extrema, porque passa a trazer severas limitações à possibilidade de cada indivíduo construir a própria realidade, na medida em que não tem saúde para tanto. Uma democracia que entenda o indivíduo como integralmente envolvido com influência normativa (dos diversos aspectos de sua vida) tem necessariamente que se preocupar com a pessoal em caráter integral.

Sendo assim, tem-se aqui um conjunto de metas voltadas para o atendimento das necessidades mais básicas do ser humano. Os Objetivos do Milênio aqui apontados demonstram a preocupação da Organização das Nações Unidas (ONU) com o fato de que as pessoas devem ter condições mínimas de sobrevivência, partindo-se da ideia de que as pessoas devem não apenas sobreviver, mas fazê-lo sem estarem submetidas à fome e à extrema pobreza. Tais questões se relacionam de maneira muito clara com a capacidade das pessoas para construir a própria realidade e, portanto, com a democracia de perspectiva construtiva. Qualquer sociedade que se pretenda democrática deve assegurar que seus cidadãos tenham o substrato essencial da dignidade da pessoa humana, para que se possa, a partir de então, atribuir-lhes formas de empoderamento, objetivando potencializar a sua capacidade de influir no mundo à sua volta. 
Aparece, ainda, como Objetivo do Milênio a universalização do ensino básico, ou seja, que todas as pessoas tenham acesso ao ensino primário. Não há como superestimar a relação entre educação e democracia, principalmente em um mundo em que o próprio Programa das Nações Unidas para o Desenvolvimento reconhece que a meta não será atingida, "devido ao lento ritmo de expansão educacional e também por conta das significativas disparidades ainda existentes, principalmente em prejuizo das meninas e das crianças das zonas rurais". Especificamente no Brasil, "a percentagem de jovens de 15 a 24 anos com pelo menos seis anos completos de estudo passou de 59,9\% em 1990, para 84\% em 2012". ${ }^{16}$ Assim, apesar dos inegáveis avanços no sentido da universalização do acesso ao ensino básico, a realidade é de que não está no horizonte o dia em que todas as pessoas terão acesso a tal direito fundamental.

Mesmo quando se trabalha com a concepção clássica de democracia (liberal), é muito estreita a dependência que a atuação democrática tem da educação, visto que a atuação política depende, se não formalmente, pelo menos materialmente de uma condição educacional mínima que viabilize uma adequada condição de mundo. Partindo-se do analfabetismo até a erudição, existe um amplo espectro de nível intelectual no qual cada pessoa pode estar localizada. Se, por um lado, é certo que a correlação entre educação e atuação política comporta exceções, por outro é evidente que, em regra, o avanço no espectro educacional vai implicar avanço no exercício da cidadania, uma vez que as pessoas com maiores níveis educacionais tendem a ser mais cientes de seus direitos e, portanto, mais disposta a defender seus pontos de vista na esfera pública.

Tal relação entre educação e democracia adquire uma intensidade várias vezes maior quando se adota umas perspectiva construtiva, uma vez que vários outros aspectos da vida da pessoa (além do político) passam a ser relevantes. Uma pessoa submetida a uma severa limitação em seu grau de educação, provavelmente vai experimentar uma severa limitação em sua capacidade de construir a própria realidade, a começar pela perspectiva profissional-financeira que lhe será oferecida. Qualquer que seja a importância que uma pessoa específica dê à questão financeira, é inegável que a capacidade da pessoa de construir a própria realidade sempre terá algum grau de vinculação com o seu rendimento periódico, uma vez que a construção da realidade passa inevitavelmente pela aquisição de bens que custam alguma quantidade de dinheiro.

Para além da questão financeira, entretanto, a educação está relacionada com inúmeros outros aspectos da vida da pessoa, senão com todos. Especificamente no que diz respeito aos procedimentos tipicamente democráticos, pode-se apontar, por exemplo, que uma educação deficiente irá impedir (ou dificultar seriamente) que a pessoa possa se colocar como elemento ativo da esfera pública, na medida em que não terá a devida capacidade de expor seus argumentos, bem como de compreender os argumentos dos demais. Em uma democracia que se apresenta como discursiva em todos os seus níveis, a educação será relevante em todos os momentos e em especial naqueles em que a realidade precisar ser 
construída em conjunto com outros interessados. Desse modo, buscar a universalização da educação básica significa buscar uma melhoria da democraticidade de qualquer sociedade, notadamente quando se adota a perspectiva construtiva.

Também está elencado como Objetivo do Milênio é a igualdade entre os sexos e a autonomia das mulheres, o que se mostra fundamental mesmo para a concepção usual de democracia, segundo a qual a igualdade é uma marca fundamental. Efetivamente, como se expôs no tópico inicial, desde Alexis de Tocqueville que a democracia passou a trazer em si a igualdade como elemento constitutivo: trata-se de um sistema voltado para a construção de normas a partir da deliberação livre dos interessados que são tidos como iguais. Essa igualdade naturalmente não se aplica apenas aos homens entre si, mas também às mulheres, sendo inadmissível a discriminação de gênero. Destaque-se que essa percepção se mostra convergente também com outro fundamento da democracia clássica, qual seja, a universalidade. Qualquer concepção de democracia no século XXI exige que as mulheres sejam não apenas incluídas no processo democrático, como também que sejam tratadas com igualdade.

Porém, quando se muda o paradigma democrático e passa-se a adotar a perspectiva construtiva, a coisa muda completamente de dimensão. Nesse momento, já não é mais satisfatório um tratamento das mulheres baseado em uma igualdade formal, segundo a qual elas têm direito de voto e (eventualmente) podem ocupar cargos públicos eletivos. A partir do ponto em que se investiga a capacidade que determinada sociedade reserva às mulheres para construir a própria realidade, então a autonomia das mulheres adquire relevância e passa a fazer parte da equação democrática. Sob essa ótica, fica evidente a necessidade de que a mulher seja reconhecida como um ser plenamente dotado de autonomia, o que significa reconhecer que ela tem capacidade total de fazer as próprias escolhas, bem como responder pelas consequências delas.

Sendo assim, não é apenas a exclusão política das mulheres que vai interessar a democracia, mas sim uma análise do seu papel em determinada sociedade. Sem dúvida, existe um ganho democrático quando uma sociedade reconhece os direitos políticos das mulheres (como aconteceu em quase todo o Ocidente na primeira metade do século XX), entretanto a questão democrática não se esgota aí. Isso ocorre porque não se pode falar em democracia quando as mulheres permanecem vítimas de outros tipos de discriminação, como a proibição de frequentar a escola, dirigir, sair à rua sem o marido ou escolher a própria roupa. Independentemente do regime político que adote, uma sociedade que apresente tais características é essencialmente autoritária, na medida em que se verificam severas restrições à capacidade das mulheres de construir a própria realidade.

Consta ainda como Objetivo do Milênio o projeto de garantir a sustentabilidade ambiental, o que se traduz na intenção de:

a) integrar os princípios do desenvolvimento sustentável nas políticas e programas nacionais e reverter a perda de recursos ambientais; 
b) reduzir significativamente a perda da diversidade biológica;

c) reduzir pela metade a proporção da população sem acesso permanente à água potável e ao esgotamento sanitário e;

d) alcançar uma melhoria significativa na vida da população urbana que vive em bairros degradados.

De maneira geral, portanto, o sétimo objetivo do milênio consiste em uma política ambiental que não apenas proteja o meio ambiente em si, mas se preocupe em oferecer às pessoas um meio ambiente saudável para que possam viver a sua vida com dignidade.

A existência de um meio ambiente que é mantido de maneira sustentável pode ser relacionada diretamente com a democracia construtiva, como se pode perceber das especificações apresentadas pelo próprio Programa das Nações Unidas para o Desenvolvimento. Em uma situação ordinária, a capacidade das pessoas de construir a própria realidade está diretamente vinculada ao meio ambiente no qual elas vivem, motivo pelo qual faz sentido sugerir que ele seja explorado de maneira sustentável, inclusive no que se refere à manutenção da diversidade biológica e à preservação dos recursos ambientais. De forma mais expressiva, percebe-se que pode haver sérias limitações à capacidade construtiva das pessoas, se elas vivem em um ambiente no qual não lhes é assegurado o acesso à água potável ou a ao esgotamento sanitário adequado.

Não é à toa, portanto, que a garantia da sustentabilidade ambiental compreende expressamente o objetivo de alcançar uma melhoria significativa na vida da população urbana que vive em bairros degradados. As pessoas são, em muitos níveis de sua existência, diretamente afetadas pelo meio ambiente em que vivem. Sendo assim, faz sentido que exista uma preocupação efetiva com a preservação do meio ambiente, bem como que essa questão seja relacionada com a democracia construtiva. A partir do momento em que se trabalha com o paradigma de que as pessoas devem ter o máximo de influência possível na construção da própria realidade, então o meio ambiente sustentável passa a ser uma questão primordial a ser abordada e enfrentada com seriedade, na busca de assegurar uma maior autonomia.

Por fim, tem-se como Objetivo do Milênio o estabelecimento de uma parceria global para o desenvolvimento, consistente em:

a) avançar no desenvolvimento de um sistema comercial e financeiro aberto, baseado em regras, previsível e não discriminatório;

b) atender as necessidades especiais dos países menos desenvolvidos (como a redução da dívida externa);

c) atender as necessidades especiais dos países sem acesso ao mar e dos pequenos Estados insulares em desenvolvimento;

d) tratar globalmente o problema da dívida dos países em desenvolvimento, de modo a torná-la sustentável a longo prazo; 
e) formular e executar estratégias para que os jovens dos países em desenvolvimento obtenham um trabalho digno e produtivo;

f) proporcionar, nos países em desenvolvimento, o acesso a medicamentos essenciais a preços acessíveis e;

g) tornar acessíveis os benefícios das novas tecnologias, em especial aquelas relacionadas à informação e à comunicação.

De uma maneira geral, pode-se dizer que o oitavo Objetivo do Milênio se relaciona com a pretensão de diminuir o subdesenvolvimento no mundo, o que faz que ele se relacione com muitos dos outros objetivos. Seu foco não é exatamente combater um problema específico ou promover um direito humano em especial, mas sim assegurar toda uma classe de vantagens para os países em desenvolvimento, para que eles possam desenvolver-se com maior velocidade. Como é óbvio, uma meta como essa tem um alcance gigantesco, na medida em que bilhões de pessoas moram em países considerados em desenvolvimento, ou seja, o Objetivo (final) do Milênio é fazer que os avanços civilizatórios não estejam reservados a quem vive nos países desenvolvidos, mas também possa ser objeto de fruição por uma parcela mais significativa da população mundial.

Em outras palavras, o que se pretende é universalizar o desenvolvimento. Como não perceber de plano a relação existente entre esse objetivo e o conceito de democracia construtiva? Atualmente, bilhões de pessoas vivem em países cujo estágio de desenvolvimento lhes impõe severas restrições de diversas naturezas, o que limita a sua capacidade de construir a própria realidade, seja mediante falta de informação, seja pela inexistência de uma colocação decente no mercado de trabalho. Coordenar um esforço global para a aceleração do desenvolvimento dos países em estágio mais atrasado é um objetivo essencialmente democrático, visto que versa sobre o aumento do empoderamento das pessoas que moram nesses países e verão no (eventual) desenvolvimento uma mudança real da sua capacidade construtiva.

Como é possível ver, então, a partir de uma perspectiva construtiva, os Objetivos do Milênio relacionam-se diretamente com a questão democrática, apresentando-se mesmo como pressupostos de um Estado que pretenda ostentar essa característica. Efetivamente, após um período de 25 (vinte e cinco) anos (que se estende de 1990 a 2015), ainda que todas as metas estabelecidas não tenham sido plenamente atingidas, é fato que se caminhou de maneira significativa no sentido de um mundo no qual as pessoas têm mais capacidade de construir a própria realidade, mediante a promoção de direitos fundamentais que lhes garantem maior influência sobre o mundo no qual vivem. Por tal motivo, é fundamental ressaltar sempre a conexão existente entre a democracia e todas as dimensões dos direitos sociais, para que se perceba que uma democracia exclusivamente representativa/indireta não passa de uma ficção, sem poder transformador sobre a vida das pessoas. 


\section{CONCLUSÃO: UMA "NOVA" DEMOCRACIA}

Durante os últimos 25 (vinte e cinco) séculos, o conceito de democracia passou por uma série de inúmeras mudanças, até se consolidar na segunda metade do século XX como um sistema no qual todas as pessoas que compõem uma sociedade têm o direito de manifestar seu pluralismo, mediante um processo partidário-eleitoral no qual lhes é assegurada a igualdade. Algumas décadas atrás, tratava-se de uma conquista sem precedentes, que finalmente consagrava as propostas veiculadas pelas revoluções liberais dos séculos anteriores. A maior prova do avanço de tal tecnologia de governo é o fato de que até hoje dezenas de países ainda se encontram à margem dessa contribuição teórica, buscando implementar uma democracia funcional, enquanto se veem submetidos a governos autoritários e ditatoriais.

Transposto o limiar do terceiro milênio, entretanto, a conquista se apresenta como ultrapassada. Se não em razão de sua inadequação, certamente em razão de sua insuficiência. Efetivamente, em pleno século XXI, deve ser tido como superado um conceito de democracia essencialmente liberal, que se concentra em um procedimento formal modulado pelos direitos fundamentais de primeira dimensão e proporciona uma democracia limitada à participação indireta e representativa. A realidade atual exige mais. Exige uma democracia que amplie, de maneira, significativa a participação das pessoas, sendo, na medida do possível, direta. Ademais, exige uma democracia que seja capaz de dialogar com todas as dimensões dos direitos fundamentais, que hoje são universalmente consideradas como elementos constitutivos da ideia de dignidade da pessoa humana.

Uma vez que a democracia clássica não se mostra apta a comportar a inclusão de tais contribuições teóricas, propõe-se o conceito de democracia construtiva, como novo paradigma, que parte da ideia de que o nível de democracia de uma sociedade deve ser medido pela capacidade que as pessoas têm de construir a própria realidade. Trata-se de uma alternativa apta a dialogar com a complexidade que se apresenta no século XXI, sem desconsiderar que a representação continua a ser um instrumento de funcionalidade do sistema, embora tenha perdido o seu papel de centralidade. Mediante a adoção desse novo conceito, faz-se possível a recepção de todas as dimensões dos direitos fundamentais, pois o objeto de interesse da democracia construtiva é significativamente mais amplo do que o da democracia clássica, abrangendo todos os aspectos da vida das pessoas.

A partir da adoção desse novo paradigma, passa a ser possível trabalhar os Objetivos do Milênio sob a perspectiva democrática, na medida em que não podem mais ser vistos como questões sem qualquer relação com o debate democrático. De fato, à medida que se passa a conceber a democracia como a capacidade de cada um para influir na construção da própria realidade, então fica evidente que os Objetivos do Milênio interessam diretamente à democracia. As metas estabelecidas pelo Programa das Nações Unidas para o Desenvolvimento são formas de aumentar a inclusão de bilhões de pessoas no desenvolvimento, o que impacta diretamente no espectro de possibilidades que elas passam a ter na 
própria vida. Promover empoderamento das pessoas é promover a sua capacidade construtiva e, portanto, a democracia.

No século XXI, não é mais admissível que se trabalhe com uma democracia liberal, que privilegie a igualdade formal em detrimento da realidade. $\mathrm{O}$ desafio do novo milênio é encontrar um paradigma que se mostra capaz de refletir a convergência que todas as dimensões dos direitos fundamentais têm, enquanto perspectivas complementares da dignidade da pessoa humana. Acredita-se que essa compatibilização pode ser efetivada no âmbito da democracia, desde que se adote uma perspectiva construtiva, capaz de trabalhar com as pessoas como seres holísticos que efetivamente são. É imperativo compreender que os Objetivos do Milênio e a democracia fazem parte de uma mesma realidade que diz respeito a aspectos essenciais da vida das pessoas, motivo pelo qual devem ser encarados como abordagens complementares do desenvolvimento. Este trabalho é uma contribuição nesse sentido.

\section{REFERÊNCIAS}

ARON, Raymond. Democracia y totalitarismo. Barcelona: Editora Seix Barral, 1968.

GOYARD-FABRE, Simone. O que é democracia. São Paulo: Martins Fontes, 2003.

HABERMAS, Jürgen. Direito e democracia. Rio de Janeiro: Tempo Brasileiro, 2003. HONNETH, Axel. Luta por reconhecimento. São Paulo: Editora 34, 2003.

KELSEN, Hans. A democracia. São Paulo: Martins Fontes, 2003.

OBER, Josiah. Origins of democracy in Ancient Greece. Los Angeles: University of California Press, 2006.

SEN, Amartya. Desenvolvimento como liberdade. São Paulo: Companhia das Letras, 2000.

TOCQUEVILLE, Alexis de. Da democracia da América. São João do Estoril: Principia, 2007.

1 OBER, Josiah. Origins of democracy in Ancient Greece. Los Angeles: University of California Press, 2006.

2 GOYARD-FABRE, Simone. O que é democracia. São Paulo: Martins Fontes, 2003.

3 TOCQUEVILLE, Alexis de. Da democracia da América. São João do Estoril: Principia, 2007.

4 HABERMAS, Jürgen. Direito e democracia. Rio de Janeiro: Tempo Brasileiro, 2003.

5 TOCQUEVILLE, Alexis de. op. cit.

6 KELSEN, Hans. A democracia. São Paulo: Martins Fontes, 2003.

7 ARON, Raymond. Democracia y totalitarismo. Barcelona: Editora Seix Barral, 1968.

8 Deve-se ter presente que, até aqui, não se está considerando as possibilidades de uma participação direta viabilizada por meios eletrônicos, como sugerido por alguns. 
9 Quanto ao último exemplo, certamente é possível abrir uma discussão a respeito da necessidade de se restringir a liberdade dos pais de colocar em seus filhos de maneira que seja considerada vexatória. Sem prejuízo de se admitir eventual limitação, é possível afirmar com segurança que, na esmagadora maioria dos casos, a escolha dos nomes dos filhos é uma mera questão de gosto dos pais, sem que ninguém mais tenha interesse legítimo em interferir na definição.

10 Aqui deve ficar clara que a definição daquilo que será objeto de regulação acontece efetivamente na esfera política, sendo o direito o meio utilizado para viabilizar a intervenção. A própria questão de estabelecer o que tem relevância jurídica é uma operação que acontece numa zona de penumbra entre a política e o direito.

11 HABERMAS, Jürgen. op. cit.

12 No presente trabalho, faz-se a opção por usar o termo "dimensão" e não "geração" para se referir a cada grupo de direitos fundamentais. Tal opção se deve ao fato de que a expressão mais consagrada (gerações) pode levar a uma confusão consistente em se pensar que os direitos de geração mais recente superam os direitos das gerações anteriores, como foi pensado, por exemplo, nos estados comunistas, cuja prevalência dos direitos sociais implicava restrição das liberdades civis e políticas. O termo dimensão, entretanto, parece mais preciso, na medida em que cada novo grupo de direitos fundamentais que surge acaba por redimensionar o princípio da dignidade da pessoa humana, sendo este um ponto de convergência no qual se impõe a convivência harmônica de todos os direitos fundamentais, em um entendimento compatível como Estado Democrático de Direito.

13 SEN, Amartya. Desenvolvimento como liberdade. São Paulo: Companhia das Letras, 2000.

14 Eventualmente é possível verificar que os debates a respeito da democracia acabam por resvalar nos direitos fundamentais de todas as dimensões (indo além dos direitos civis e políticos). Notadamente depois da II Guerra Mundial, o século XX foi marcado por uma preocupação constante de que limites meramente formais dessem margem para condutas arbitrárias e afrontosas aos direitos humanos. Os limites de tais abordagens, entretanto, ficam apenas tangencialmente relacionados com a democracia, caso ela seja entendida sob a perspectiva representativa. A mudança para uma perspectiva construtiva possibilita uma interação muito mais profunda entre a democracia e todas as dimensões dos direitos fundamentais, que passam a ser entendidos como seus elementos constitutivos.

15 HONNETH, Axel. Luta por reconhecimento. São Paulo: Editora 34, 2003.

16 As informações sobre a realização de cada um dos pontos foram retiradas do endereço <http://www.pnud. org.br/Docs/5_RelatorioNacionalAcompanhamentoODM.pdf>, no qual consta o documento "Objetivos de Desenvolvimento do Milênio: Relatório Nacional de Acompanhamento".

\title{
MILLENNIUM DEVELOPMENT GOALS AND CONSTRUCTIVEDEMOCRACY:FUNDAMENTAL RIGHTS AS CONSTITUTIVE ELEMENTS OF THE DEMOCRATIC RULE OF LAW
}

\begin{abstract}
This paper aims at demonstrating how the achievement of the Millennium Development Goals is a precondition for the construction of the Democratic Rule of Law. This involves initially presenting a discussion on the concept of democracy, in order to demonstrate that it can no longer, in the $21^{\text {st }}$ century, be viewed merely as a limited right of political participation and that it should be understood as the ability that one has to build their own reality. From this concept, the article seeks to overcome the paradigm of
\end{abstract}


classical liberal democracy, through the discussion of the idea according to which the active process of democracy requires that every person has the effective capacity to exercise their citizenship, which relies upon them being offered a number of opportunities that are essential to their development. In this context, the article states that the Millennium Development Goals stand out, because they represent minimum elements for the conditions for a dignified life, without which it is impossible to speak of the construction of one's own reality. Finally, the article argues that the commitment to achieving the Millennium Development Goals reflects partly the commitment to implement the Democratic Rule of Law, in that it is an appropriate step in the expansion of the capacity for effective participation of the people that make up a given society.

Keywords: Democracy. Constructive Perspective. Millennium Development Goals. Constitutive Function.

Submetido: 19 out. 2015

Aprovado: 13 maio 2016 